\title{
Daunorubicin-DNA Complex
}

National Cancer Institute

\section{Source}

National Cancer Institute. Daunorubicin-DNA Complex. NCI Thesaurus. Code C1061.

A complex comprised of Daunorubicin linked to DNA to enhance the topoisomerase IImediated interaction with the DNA base pairs and reduce cardiotoxicity associated with anthracyclines. ( $\mathrm{NCl})$ 